\title{
The complex relationship between immigrants' concentration, socioeconomic environment and attitudes towards immigrants in Europe
}

\section{Rezart Hoxhaj \& Carolina V. Zuccotti}

To cite this article: Rezart Hoxhaj \& Carolina V. Zuccotti (2020): The complex relationship between immigrants' concentration, socioeconomic environment and attitudes towards immigrants in Europe, Ethnic and Racial Studies, DOI: 10.1080/01419870.2020.1730926

To link to this article: https://doi.org/10.1080/01419870.2020.1730926

曲 Published online: 05 Mar 2020.

Submit your article to this journal $\widetilde{ }$

Џ Article views: 75

Q View related articles 5

View Crossmark data \lceil 


\title{
The complex relationship between immigrants' concentration, socioeconomic environment and attitudes towards immigrants in Europe
}

\author{
Rezart Hoxhaj and Carolina V. Zuccotti \\ Migration Policy Centre, RSCAS, European University Institute, Florence, Italy
}

\begin{abstract}
Research has shown that positive attitudes towards immigration are often associated with a higher presence of immigrants at the local level; however, this relationship might not apply everywhere. While a higher presence of immigrants might be positive for attitudes in areas with better socioeconomic resources via the development of more cooperative intergroup contacts - it might bring no or even a negative effect on attitudes in poorer areas - due to an enhanced competition for (scarce) resources and poorer social cohesion. This article combines data from the European Social Survey with NUTS3 aggregated data of twelve European countries to study this relationship. We find that a higher concentration of immigrants is associated with more positive attitudes towards them; in line with our expectations, this effect decreases as the socioeconomic conditions of areas worsen. In the most deprived areas, however, a higher concentration of immigrants does not have an effect on attitudes.
\end{abstract}

ARTICLE HISTORY Received 13 June 2019; Accepted 11 February 2020

KEYWORDS Attitudes; immigrant concentration; Europe; NUTS3; socioeconomic context; refugee distribution

\section{Introduction}

The relationship between the spatial location of immigrants and attitudes towards immigration remains a key issue in the migration research agenda (Kaufmann and Harris 2015; Tam Cho and Baer 2011) and, more generally, in the public and policy debate. Specifically, a key question is whether an increase in the physical presence of immigrants - in the streets, in the neighbourhoods, at work, on the bus, at school - exerts a positive or a negative effect on how the majoritarian populations in destination countries perceive these immigrants.

Studies find that individuals who reside in neighbourhoods or areas (i.e. provinces, small regions) with a higher immigrant concentration have, in 
general, more positive views towards immigration compared to individuals who live in native majoritarian areas (see Kaufmann and Harris 2015). Contact theory, which states that prejudice can reduce by means of (positive) contact with others, is a commonly used framework for explaining this finding (Pettigrew 1998; Pettigrew and Tropp 2006). However, this effect might not always occur. Following the arguments posed by Quillian (1995), we argue that the socioeconomic characteristics of the area might affect this relationship. While contact with immigrants might be positive for attitudes in areas that are better off - e.g. with more availability of jobs, better infrastructure, etc. - a higher presence of immigrants might bring no or even a negative effect on attitudes in areas with poorer (i.e. scarcer) resources. Competition or threat - rather than positive contact - would be the main explanatory effect (Blumer 1958). There is already some evidence in the literature showing this effect. For example, Hjerm (2009) finds for Sweden that people have stronger anti-immigrant attitudes in municipalities where unemployment is high and the proportion of foreign-born people is larger. Similar findings are observed in Branton and Jones (2005), who study attitudes towards immigration policy in the US.

Using data from the European Social Survey (2014), a cross-national dataset covering the most common destination countries in Europe, in combination with aggregated data collected at the NUTS3 $^{1}$ level (small regions), the study answers the following questions:

- What is the relationship between attitudes towards immigration and immigrant concentration in the area of residence?

- Is this relationship conditioned by the socioeconomic characteristics of the areas? If so, in which way?

Our study contributes to the European literature on the role of local contexts on attitudes towards immigration in different ways. First, the large majority of studies focuses on the effect of immigrant concentration on attitudes solely (Semyonov and Glikman 2009; Weber 2015; Markaki and Longhi 2013). We improve these analyses by exploring how such effect might vary according to the socioeconomic characteristics of areas. A second, and related, contribution regards how we deal with such conditionality. Most of research that has included the interaction between immigrant concentration and socioeconomic context in their analysis, base their findings solely on the interpretation of the interaction coefficient (e.g. Quillian 1995; Branton and Jones 2005; Hjerm 2007, 2009; Oliver and Mendelberg 2000). However, when studying interaction terms it is important to evaluate - both substantively and in terms of statistical significance - how the effects play out in different parts of the distribution (Brambor, Clark, and Golder 2006; Hainmueller, Mummolo, and Xu 2018). Section "Possible scenarios" presents different 
scenarios of how this might occur, and discusses the implications for contact and threat theories. Our findings reveal that while the relationship between immigrant concentration and attitudes is conditioned by the socioeconomic conditions of local areas in the expected direction, this effect cannot be confirmed throughout the socioeconomic distribution. A third contribution is that we explore the conditionality at a relatively small geographical scale (NUTS3), thanks to permission granted by the board of European Social Survey. In a systematic review, Kaufmann and Harris (2015) show that, in general, the smaller the geographical areas for which immigrant composition is measured - which presumably better captures intergroup contact (Pettigrew 1998) - the more positive attitudes towards immigration are. A recent cross-national study (Weber 2015), based on the European Values Study, demonstrates these differentiated effects of areas' sizes. It shows that a positive effect of immigrant concentration on attitudes occurs only when the proportion of immigrants is measured at the NUTS3 level, but not when measured at higher levels (NUTS2/ NUTS1). Our study, therefore, first confirms Weber's finding; and then goes a step further by exploring the combined role of immigrant concentration and areas' socioeconomic characteristics on attitudes.

The article is organized as follows. The second section presents the theoretical approach. In the third section, we describe the data and methodology. The fourth section presents our empirical findings. Finally, we conclude and discuss our findings in the last two sections.

\section{Theoretical background}

Whether individuals hold more positive or more negative attitudes towards immigrants depends on a high range of factors, including individual characteristics of both immigrants and natives (Ceobanu and Escandell 2010) and contextual/macro characteristics, such as those measured at the regional (Markaki and Longhi 2013) and country levels (Callens and Meuleman 2017; Ruist 2016). A particularity of these studies, and of many social science studies in general, is that conditionality is often a secondary aspect of the analyses. That is, an individual's education, or a country's GDP or the number of immigrants in a region, are often considered as additive explanations of attitudes. However, as the literature on intersectionality has explicitly highlighted (Collins 2015), it is often the case that some relationships hold - or become stronger or milder - for some specific groups or in particular contexts (see also Billiet, Meuleman, and De Witte 2014). In terms of our research, while there is a large number of studies that have explored the role of immigrant concentration on natives' attitudes (Kaufmann and Harris 2015; Hooghe and de Vroome 2015), there is a shortage of studies that consider the complexities of such contexts, especially as regards the socioeconomic characteristics of 
areas (some exceptions are Hjerm 2009; Branton and Jones 2005; Quillian 1995). Our study brings evidence into this research agenda.

\section{Attitudes and context: key explanatory mechanisms}

Independently of whether we are studying the impact of individual characteristics or of contextual characteristics on attitudes, when trying to disentangle the mechanics behind these relationships it is of great importance as to whether immigrants appear as a threat or not. The more an immigrant appears as a menace to an individual's or a group's socioeconomic status, religion or culture, the more negative these views will be. Conversely, the more an individual or a group identifies with other individuals' or groups' values, or the more an individual has acquired the tools connected to tolerance and acceptance of diversity, the more these views will be positive. A relevant question is, therefore, what triggers threat? Or conversely, what triggers tolerant attitudes?

Studies that analyse the relationship between the immigrant composition of areas and attitudes towards immigration often discuss two potential theories that explain how this relationship might occur. These studies do not necessarily assume (and, in most cases, do not measure) daily contact between immigrants and native populations. However, their common guiding premise is that the physical presence of immigrants in the area of residence (be this the neighbourhood, region, country, etc.) may influence how individuals think of them.

According to intergroup contact theories (Pettigrew 1998; Pettigrew and Tropp 2006), exposure or contact with members of other groups, which inevitably happens in areas with a higher share of immigrant population, should lead to greater familiarity with these groups and, hence, to enhance linking for those groups. Although Allport (1954) argues that some conditions (equal status between the groups in the situation, common goals, intergroup cooperation, and the support of authorities, law, or custom) are necessary for intergroup contact to exert positive effects on attitudes, Pettigrew and Tropp (2006) show that positive attitudes may develop even if those conditions are not present. In contrast, intergroup threat theories, suggest that increased contact or exposure with immigrants will lead to increased negative views towards them (Quillian 1995). Feelings of threat may emerge for different reasons. Social-psychological explanations argue that individuals create their own identities by means of identifying themselves with - while, at the same time, differentiating themselves from - different types of groups. Next to the creation of identities, the development of prejudices and stereotyping also emerges as a parallel process (Blumer 1958). The arrival of individuals who come with different cultures, who speak a different language, who behave differently, constitute per se a potential threat to these group 
identities. At the same time, threat might also emerge through more rational reasoning, especially in terms of cost-benefit relationships (Markaki and Longhi 2013; Citrin et al. 1997). For example, a concern about the personal socioeconomic situation, or that of the area of residence or the country, might lead some to see immigrants as a competitors for scarce resources (Coenders and Scheepers 2008; Blalock 1967). That is, as increased numbers of ethnic or racial minorities compete for jobs, housing, and other economic resources, the majoritarian population might increasingly feel that their economic well-being and dominance are threatened (Wang and Todak 2016). Threat explanations might also exacerbate for more "visible" immigrants, those who come with more different cultures, or even those who come with fewer socioeconomic resources, who might be seen as a "burden" to the welfare state (Markaki and Longhi 2013).

Whether one theory prevails over the other might be due to a large number of factors, associated not only to individuals' personal characteristics and experiences, but also to additional characteristics of the areas where they live - the focus of this article. In other words, a more detailed characterization of the local context in which intergroup contacts (potentially) develop can provide with a more nuanced understanding of when threat and positive contact mechanisms are more likely to emerge. In line with previous studies (Hjerm 2007, 2009; Branton and Jones 2005; Quillian 1995), we argue that the socioeconomic conditions of the areas in which individuals reside might condition how they react to an increase in the share of immigrants. Living in areas with poorer socioeconomic conditions often leads to greater exposure to crime, social disorder, and physical decay (Branton and Jones 2005); spatial deprivation has also been shown to exert negative effects on individuals' outcomes, such as their employment and educational opportunities (Feng, Flowerdew, and Feng 2015; Fleischmann et al. 2012), but also their levels of mortality and health (Boyle, Norman, and Rees 2004). These processes might not only increase the groups' competition for resources, but also affect daily relationships and hence how individuals observe outgroup members. A study in the UK shows, for example, that there is a negative relationship between neighbourhood deprivation and social cohesion, including values such as trust, cooperation, tolerance and respect (Stafford et al. 2003). Poorer social cohesion might in turn affect individuals' attitudes towards immigrants. We therefore hypothesize that for individuals living in areas with poorer socioeconomic conditions, an increase of immigrants might lead to increased feelings of threat, or to less positive attitudes towards immigrants, compared to individuals immersed in contexts with better socioeconomic resources.

\section{Possible scenarios}

As said at the introduction, an added value of our study is that we will explore to what extent the conditionality occurs at different levels of areas' 
socioeconomic characteristics. Figure 1 below presents different possible scenarios in terms of how the relationship between share of immigrants and attitudes might be affected by the socioeconomic conditions of areas (in this case, percentage of unemployed people). While all scenarios share the same type of relationship (expressed in the inverted slope), their differences lie in the extent to which threat and contact explanations prevail.

Specifically, Figure 1 presents three different graphs in which the marginal effect of the share of immigrants on attitudes is plotted against the unemployment rate; in all cases the relationship is plotted following the article's main expectation, that is, more positive attitudes in better off areas (black line; inverted slope). In the first case (A), the effect of share of immigrants on attitudes is always positive (the line is above the zero dashed line); this would go in line with (positive) contact theory and with what most studies find, that is, that a higher share of immigrants in the local area leads to more positive views towards them. The inverted slope reveals, in line with our expectation, that this positive effect will be less as the socioeconomic conditions of areas worsen (e.g. areas with a higher share of unemployed people). In other words, scenario A suggests, first, that an increase of immigrants has a positive effect on attitudes across all areas (independently of their unemployment level); and second, that this effect is less strong in areas of higher unemployment. As argued before, this, of course, might indicate the presence of threat mechanisms, although they would not prevail, on average. We could also think of a second scenario (B) in which an increase in the share of immigrants has always a negative effect on attitudes (the black line is below the zero dashed line), as would be expected following threat theory. In terms of our argument, this scenario would suggest, first, that an increase of immigrants has a negative effect on attitudes across all areas; and second, that this

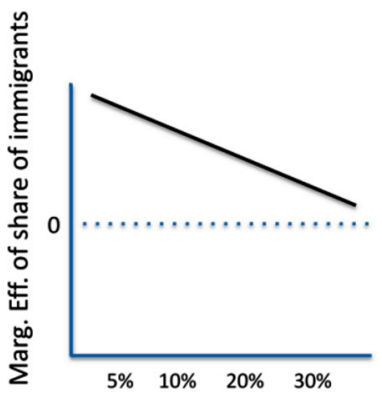

(a)

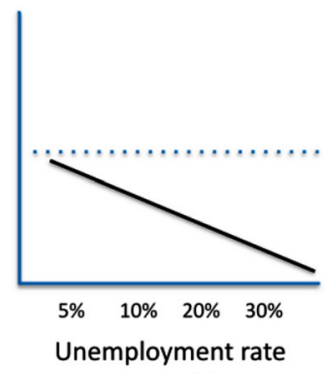

(b)

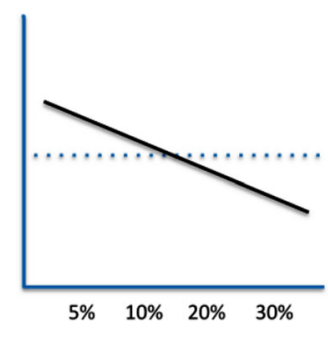

(c)

Figure 1. The marginal effect of the share of immigrants on attitudes conditional on the unemployment rate. Three different scenarios: (a) Predominance of (positive) contact, (b) Predominance of threat and (c) A threshold: a combination of (positive) contact and threat. 
effect is stronger in areas of higher unemployment. As we see, the slope would be the same, but here threat (rather than positive contact) would predominate as main explanation. The poorer socioeconomic conditions would therefore exacerbate the already present negative relationship between share of immigrants and attitudes towards them. The third scenario (C) is a mix of both, and here we could think of a threshold effect, that is, a certain level of socioeconomic characteristics that shifts the relationship between share of immigrants and attitudes from positive to negative. This graph shows that an increase in immigrants has only a positive effect on attitudes in areas that have from middle to low unemployment rates, while in areas that have from middle to high unemployment rates, an increase of immigrants has a negative effect on attitudes.

While, according to our literature review, it is quite unlikely that we find a pattern like the one in Graph B - since a higher presence of immigrants at the local level often has, on average, a positive effect on attitudes (Kaufmann and Harris 2015) - whether we observe the effects in scenario A or scenario C, and whether any of these effects is significant from a statistical point of view, is an empirical question that we explore in this article. As complementary analysis, we compare the effect of the share of immigrants from inside and outside Europe; in particular, we would expect threat to be a more common explanatory mechanism when focusing on non-European migrants (Markaki and Longhi 2013).

\section{Methodology}

\section{Data and key variables}

For our analysis, we use the seventh round of the European Social Survey (ESS henceforth), carried out in 2014-2015. The ESS is a standardized cross-sectional survey collecting information on attitudes toward immigrants and other relevant individuals' socio-demographic characteristics across twentyone European countries. This survey is representative of all individuals above fifteen years of age in each country. The ESS is appropriate to conduct cross-country comparisons since attitudes towards immigrants are equivalently measured across countries (Davidov, Cieciuch, and Schmidt 2018). We chose the seventh round because it has a special module on immigration and, hence, a wider range of variables on attitudes. In addition, the difficulties associated with obtaining NUTS3 geographies for ESS respondents, plus those related to finding contextual data at the NUTS3 level, made us restrain our analysis to one ESS wave rather than to multiple ones.

We focus our analysis on native individuals, defined here as those born in the European countries under study and who have at least one parent born in the same country. Attitudes towards immigrants are measured using a combination of seven questions for which respondents need to provide an 
evaluation on whether immigrants worsen or improve the life in the country, and more specifically, on whether immigrants present an economic, cultural/ religious or public threat to the country. Table A1 in the supplemental online material shows the precise formulation of these questions/items. For each question, individuals need to position themselves in a scale that ranges from zero (negative attitudes) to ten (positive attitudes).

Our dependent variable, attitudes towards immigrants, is a normalized variable (ranges from 0 to 1 , where 1 refers to attitudes that are more positive) that combines the scores of all seven questions. ${ }^{2}$ A Cronbach's Alpha test gives a score equal to 0.86 . In alternative to this specification, and for some analyses only, we have also used an indicator of attitudes that captures economic threat specifically. This variable is a summary of three questions measuring attitudes on economic issues only (questions 1,2 and 3 in Table A1), and varies between 0 and 1 (where 1 is less economic threat). A Cronbach Alfa test gives a score equal to 0.76 .

Data on contextual characteristics were obtained for NUTS3 geographies (further details in endnote \#1). Although NUTS3 can be very varied in terms of the population they contain (see Table A2 in the supplemental online material), they are the smallest geographical unit that can be attached to ESS data. In some cases, this geographical reference was already included as a variable in ESS data; in other cases, we obtained this information through a special licence provided to us by the ESS coordination. Overall, we were able to obtain 422 NUTS3 areas from twelve European countries. The size of NUTS3 is also appropriate for proxying competition for jobs and the greater exposure to diverse individuals that this implies (Oliver and Mendelberg 2000). ${ }^{3}$

Contextual, and key independent, variables used in this study are immigrant concentration, operationalized as share of immigrants in NUTS3 (share of all immigrants over the total population), and socioeconomic characteristics of NUTS3 (unemployment rate and GDP per capita). The latter have been previously used by similar research to proxy the economic situation of an area and its level of development/wealth, respectively (Markaki and Longhi 2013; Weber 2015). All contextual variables refer to the year 2011. Data on immigration, which is based on information on country of birth, was obtained from 2011 Census Hub (Eurostat 2014) ${ }^{4}$; unemployment rate and GDP per capita was obtained from the official statistics of the twelve countries under analysis (see Table A4 in supplemental online material for the sources of the data).

Table 1 shows descriptive statistics of our dependent and independent variables. Column (A) displays the statistics concerning attitudes towards immigrants. In countries such as Sweden, Finland and Germany, views towards immigrants are more positive, on average; while in Austria, Czech Republic and Hungary, views are more negative. The dispersion (standard deviation) of attitudes across NUTS3 areas is the highest in Austria, 
Table 1. Descriptive statistics.

\begin{tabular}{|c|c|c|c|c|c|c|c|c|c|c|c|c|c|c|c|c|c|}
\hline \multirow[b]{2}{*}{ Countries } & \multicolumn{4}{|c|}{ (A) Attitudes (NUTS3) } & \multicolumn{4}{|c|}{$\begin{array}{l}\text { (B) GDP per capita/000 } \\
\text { (NUTS3) }\end{array}$} & \multicolumn{4}{|c|}{ (C) Unemployment (NUTS3) } & \multicolumn{4}{|c|}{$\begin{array}{c}\text { (D) Migrant's percentage } \\
\text { (NUTS3) }\end{array}$} & \multirow[b]{2}{*}{ Number of observations } \\
\hline & Mean & SD & Min & Max & Mean & SD & Min & Max & Mean & SD & Min & Max & Mean & SD & Min & Max & \\
\hline Austria & 0.43 & 0.06 & 0.23 & 0.52 & 36 & 9 & 19.4 & 47.8 & 5.6 & 2.1 & 2.5 & 10 & 14.4 & 7.8 & 4.92 & 30.5 & 1,392 \\
\hline Czech Republic & 0.39 & 0.02 & 0.35 & 0.43 & 15.8 & 6.4 & 11.5 & 32.6 & 6.8 & 1.97 & 3.6 & 10 & 6.8 & 3.5 & 2.66 & 14.9 & 1,728 \\
\hline Germany & 0.53 & 0.06 & 0.34 & 0.65 & 31.1 & 12.8 & 16.7 & 100 & 7.6 & 3.61 & 1.8 & 16.8 & 12.6 & 5.4 & 3.63 & 31.4 & 2,469 \\
\hline Estonia & 0.51 & 0.004 & 0.5 & 0.52 & 13 & 4.7 & 8.3 & 18.2 & 12 & 0.8 & 11.2 & 13.8 & 12 & 5.4 & 6.36 & 18 & 1,185 \\
\hline Finland & 0.54 & 0.025 & 0.49 & 0.64 & 36.5 & 8 & 26.7 & 49.4 & 9.6 & 2.2 & 2.85 & 13.4 & 3.4 & 2 & 1.4 & 12.8 & 1,928 \\
\hline Hungary & 0.42 & 0.037 & 0.36 & 0.51 & 10.2 & 6 & 4.5 & 22.2 & 11 & 3.2 & 6.2 & 18.2 & 3.9 & 1.9 & 1.49 & 7.3 & 1,431 \\
\hline Ireland & 0.49 & 0.03 & 0.45 & 0.52 & 36.5 & 13.6 & 20.9 & 56.6 & 19.3 & 2.2 & 17 & 22.8 & 16.7 & 2.4 & 13.5 & 20 & 1,749 \\
\hline Latvia & 0.49 & 0.034 & 0.44 & 0.57 & 10 & 3 & 5.9 & 14.6 & 13.1 & 1.45 & 12 & 16 & 5.6 & 3.2 & 227 & 11 & 1,838 \\
\hline Poland & 0.51 & 0.05 & 0.39 & 0.61 & 10.3 & 5.4 & 5.5 & 28.7 & 7.7 & 2.7 & 3.2 & 15 & 1.5 & 1.3 & 0.39 & 5.2 & 1,121 \\
\hline Slovenia & 0.47 & 0.033 & 0.38 & 0.54 & 17.5 & 4.5 & 11.8 & 25.2 & 11.8 & 2.65 & 9 & 18.5 & 10.6 & 3.2 & 5.21 & 21.6 & 851 \\
\hline Spain & 0.48 & 0.038 & 0.38 & 0.6 & 22.6 & 5 & 15.9 & 34.2 & 21.3 & 5.8 & 10 & 33.5 & 11.4 & 5.2 & 3.4 & 21 & 1,507 \\
\hline \multirow[t]{2}{*}{ Sweden } & 0.59 & 0.024 & 0.53 & 0.68 & 42.8 & 9.3 & 32.7 & 60 & 7.7 & 1.1 & 6 & 9.6 & 13.8 & 4.7 & 4.7 & 21.1 & 1,450 \\
\hline & & & & & & & & & & & & & \multicolumn{4}{|c|}{ Total } & 16,858 \\
\hline
\end{tabular}

Source: Own calculations. European Social Survey (2014); 2011 Census data (Eurostat 2014); National Statistical Offices. 
Germany and Poland and the lowest in Estonia, Czech Republic and Sweden. In column (B), column (C) and column (D) are displayed the statistics of GDP per capita, unemployment rate and migration rate, respectively. NUTS3 differ considerably with respect to these contextual variables. For example, the dispersion of the GDP per capita across NUTS3 is more than one third of the mean in Ireland and Germany; while the dispersion of unemployment rate is half of the mean in Germany and one third in Czech Republic. The dispersion of the share of immigrants is about half of the mean in Austria, Germany and Estonia. Overall, these statistics show that a study at a more aggregate level would ignore this important heterogeneity in contextual characteristics.

\section{Estimation method}

To test our research question, we use an OLS regression as our primary estimation method ${ }^{5}$; we include clustered standard errors at the NUTS3 level to control for the fact that individuals in NUTS3 areas might share common (unobserved) characteristics - and country fixed effects or country dummies - to control for additional unobserved factors that might affect attitudes of individuals across countries. We check the robustness of our results using alternative methods and specifications, including a multilevel model, a model controlling for outliers (Verardi and Croux 2009) and an instrumental variable approach (Dustmann and Preston 2001). These are shown in the second section, in the supplemental online material. In particular, the instrumental variable approach serves to address a key concern in this article: the potential endogeneity of our results. Endogeneity might emerge because individuals choose where to live; hence, individuals with certain types of attitudes might choose areas with certain shares of immigrant population. If this is the case, the contextual effects might be overestimated. Our additional estimations addressing the issue of endogeneity provide general support for the baseline results and are discussed in detail in the supplemental online material.

The key explanatory variable of interest is the interaction between the share of immigrants at the NUTS3 level, and the socioeconomic variables, i.e. the unemployment rate and GDP per capita (log-transformed for the purposes of the estimation) at the NUTS3 level, which are added in separate models. This interaction should capture the extent to which the local socioeconomic environment conditions the effect of the share of immigrants on attitudes. Our estimations also include individual-level variables commonly used by the literature on attitudes towards immigration (Ceobanu and Escandell 2010; O'Rourke and Sinnott 2006). These are Age (number of years), Female (equal to one if the respondent is female, zero otherwise), Parent foreign born (equal to one if at least one of the parents of the respondents was 
born abroad), a set of dummies following the ISCED classification of education $^{6}$ to measure educational attainment, a set of dummies to control for the activity status (Employed, Unemployed, In education, Inactive), a set of dummies that capture political orientation (Left, Centre, Right), the ISEI index that measures occupational status and ranges between sixteen and ninety (Ganzeboom and Treiman 1996) and a set of dummies for the typology of the area of residence (City, City suburbs, Small town, Rural). For more details on the definition of variables, refer to Table A4 in the supplemental online material.

\section{Empirical results}

In Table 2, we present the results of our baseline model having as a dependent variable the general attitudes score. In model 1 and model 2 we explore the main effects of immigrants' share of contextual variables (i.e. unemployment rate and log-transformed GDP per capita, respectively) on attitudes, unconditional of individual-level controls. Consistent with the contact theory, a higher share of immigrants in the NUTS3 area of residence has a positive effect on attitudes towards immigrants. The coefficients of contextual variables show a negative association between the unemployment rate (model 1) and attitudes, and a positive association, though not significant, between the GDP per capita and attitudes (model 2). Overall, results suggest that in areas with a less favourable socioeconomic environment individuals express, on average, more negative attitudes.

In models 3-6, we show whether the effect of share of immigrants on attitudes depends on the socioeconomic environment, before (3-4) and after (56) including individual level controls. The coefficient of the interaction between the percentage of immigrants and unemployment rate is negative and statistically significant at conventional level (model 3 and model 5). It suggests, as expected, that the effect of the share of immigrants on attitudes is conditioned by the labour market conditions of the area. A clearer illustration of this effect is showed in Graph 1 in Figure 2, which resembles scenario C. Graph 1 displays the marginal effect of the share of immigrants on attitudes towards immigrants, conditional on the level of unemployment rate in NUTS3 areas. The inverted slope in the upper section of the graph shows that as the unemployment rate increases, the positive effect of exposure to an ethnically diverse environment - which as we argued goes in line with a predominance of (positive) contact theory - decreases. Note, however, that in spite of the resemblance with scenario $C$, the effect observed below the zero line (where we expected threat mechanisms to predominate) is not statistically significant. As observed, the zero line is contained within the confidence intervals. Hence, we can only confirm the finding for one part of the distribution. In other words, the conditioning effect of unemployment 
Table 2. Does the socioeconomic context condition the relationship between share of immigrants and attitudes?

\begin{tabular}{|c|c|c|c|c|c|c|}
\hline Variables & Model (1) & Model (2) & Model (3) & Model (4) & Model (5) & Model (6) \\
\hline Share Immigrants & $\begin{array}{c}0.00291^{* * *} \\
(0.000576)\end{array}$ & $\begin{array}{l}0.00224^{* * *} \\
(0.000700)\end{array}$ & $\begin{array}{c}0.00478^{* * *} \\
(0.000934)\end{array}$ & $\begin{array}{r}-0.00489^{*} \\
(0.00279)\end{array}$ & $\begin{array}{l}0.00312^{* * *} \\
(0.000947)\end{array}$ & $\begin{array}{r}-0.00554^{*} \\
(0.00292)\end{array}$ \\
\hline Unemployment & $\begin{array}{r}-0.00168^{* *} \\
(0.000758)\end{array}$ & & $\begin{array}{c}-2.03 e-05 \\
(0.000951)\end{array}$ & & $\begin{array}{c}0.000717 \\
(0.000894)\end{array}$ & \\
\hline Log GDP per capita & & $\begin{array}{l}0.00567^{*} \\
(0.00323)\end{array}$ & & $\begin{array}{c}-0.00143 \\
(0.00495)\end{array}$ & & $\begin{array}{r}-0.0103^{* *} \\
(0.00461)\end{array}$ \\
\hline $\begin{array}{l}\text { Share Immigrants } \\
* \text { *Unemployment }\end{array}$ & & & $\begin{array}{c}-0.00017^{* * *} \\
(6.71 \mathrm{e}-05)\end{array}$ & & $\begin{array}{c}-0.000164^{* *} \\
(6.80 \mathrm{e}-05)\end{array}$ & \\
\hline $\begin{array}{l}\text { Share Immigrants } \\
\text { *Log GDP per capita }\end{array}$ & & & & $\begin{array}{l}0.00072^{* *} \\
(0.00028)\end{array}$ & & $\begin{array}{l}0.00074^{* * * *} \\
(0.000279)\end{array}$ \\
\hline Age & & & & & $\begin{array}{c}-0.000323^{* *} \\
(0.000147)\end{array}$ & $\begin{array}{c}-0.000331^{* *} \\
(0.000147)\end{array}$ \\
\hline Male & & & & & $\begin{array}{c}0.00142 \\
(0.00238)\end{array}$ & $\begin{array}{c}0.00182 \\
(0.00238)\end{array}$ \\
\hline ISCED 2 & & & & & $\begin{array}{l}0.0145^{* * *} \\
(0.00552)\end{array}$ & $\begin{array}{l}0.0167^{* * *} \\
(0.00566)\end{array}$ \\
\hline ISCED 3A & & & & & $\begin{array}{r}0.0148^{* *} \\
(0.00674)\end{array}$ & $\begin{array}{r}0.0166^{* *} \\
(0.00676)\end{array}$ \\
\hline ISCED 3B & & & & & $\begin{array}{l}0.0338^{* * * *} \\
(0.00594)\end{array}$ & $\begin{array}{l}0.0346^{* * *} \\
(0.00595)\end{array}$ \\
\hline ISCED 4 & & & & & $\begin{array}{l}0.0496^{* * *} \\
(0.00666)\end{array}$ & $\begin{array}{l}0.0511^{* * *} \\
(0.00673)\end{array}$ \\
\hline ISCED 5_1 & & & & & $\begin{array}{l}0.0663^{* * *} \\
(0.00695)\end{array}$ & $\begin{array}{l}0.0675^{* * *} \\
(0.00694)\end{array}$ \\
\hline ISCED 5_2 & & & & & $\begin{array}{l}0.0823^{* * *} \\
(0.00714)\end{array}$ & $\begin{array}{l}0.0835^{* * *} \\
(0.00714)\end{array}$ \\
\hline ISEI & & & & & $\begin{array}{l}0.000898^{* * *} \\
(6.99 \mathrm{e}-05)\end{array}$ & $\begin{array}{l}0.000904^{* * *} \\
(6.95 \mathrm{e}-05)\end{array}$ \\
\hline Unemployed & & & & & $\begin{array}{c}-0.0329^{* * *} \\
(0.00701)\end{array}$ & $\begin{array}{c}-0.0328^{* * * *} \\
(0.00697)\end{array}$ \\
\hline In education & & & & & $\begin{array}{l}0.0457^{* * *} \\
(0.00581)\end{array}$ & $\begin{array}{l}0.0458^{* * *} \\
(0.00578)\end{array}$ \\
\hline
\end{tabular}


Inactive

Parent foreign born

Centre

Right

City suburbs

Small town

Rural

Constant

Observations

$0.392^{* * * *}$

(0.0136)

16,634

0.130

R-squared

$\begin{array}{cc}-0.00951^{* * * *} & -0.00913^{* * * *} \\ (0.00324) & (0.00322) \\ 0.0202^{* * *} & 0.0205^{* * *} \\ (0.00711) & (0.00701) \\ -0.0200^{* * *} & -0.0198^{* * *} \\ (0.00389) & (0.00379) \\ -0.0275^{* * *} & -0.0272^{* * *} \\ (0.00555) & (0.00548) \\ -0.00633 & -0.00841 \\ (0.00667) & (0.00621) \\ -0.00726 & -0.00990^{*} \\ (0.00652) & (0.00578) \\ -0.00605 & -0.00836 \\ (0.00682) & (0.00625) \\ 0.366^{* * *} & 0.402^{* * *} \\ (0.0208) & (0.0224) \\ 16,634 & 16,858 \\ 0.212 & 0.210\end{array}$

endent variable: Attitudes score. The estimation method used is OLS. Country dummies included in the estimations. Errors are clustered at the NUTS3 level. Total number of NUTS3 $=422$. Reference categories: For activity is employed; for education level is ISCED 1 (less than lower secondary); for urban agglomeration is urban; for political orientation is left wing. Country dummies included in the estimations. Error clustered at the NUTS3 level. Robust standard errors in parentheses. ${ }^{* * *} p<0.01,{ }^{* *} p<0.05$, ${ }^{*} p<0.1$. 

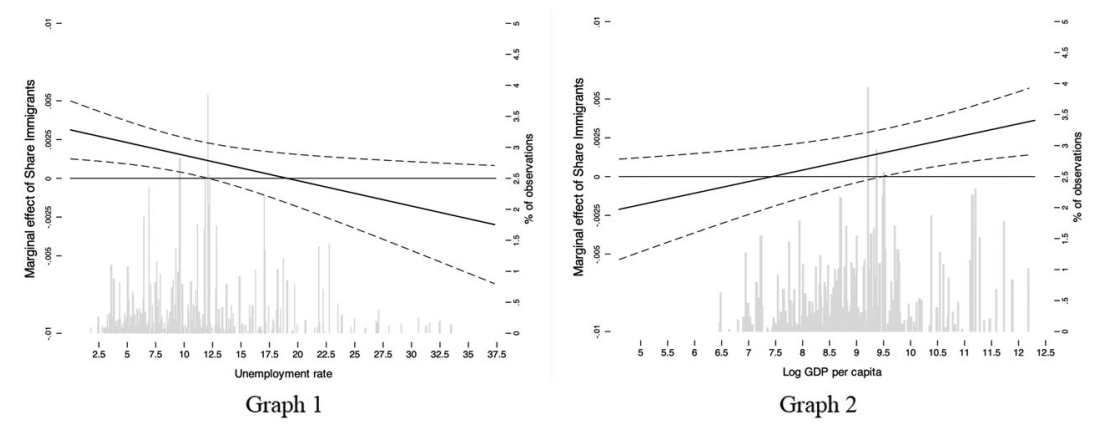

Figure 2. Illustrations of marginal effects. Dependent variable: Attitudes score. Based on Models 5 and 6 from Table 2 .

rate is relevant only for areas that are relatively better off, i.e. those with unemployment rates between 1.8 per cent and 12.1 per cent. ${ }^{7}$ This result suggests that in more deprived areas (where the unemployment level is above 12 per cent) additional immigrants do not produce an effect on attitudes (or, in this case, further intolerance).

The socioeconomic context measured by the GDP per capita tells a similar story. The coefficient of the interaction between the percentage of immigrants and GDP per capita is positive and statistically significant at the 5 per cent level (model 6). Graph 2 displays the marginal effects of the share of immigrants on attitudes, conditional on the wealth of the areas measured in terms of GDP per capita. As in Graph 1, but with the slope in the other direction, given the nature of the variable, we find that a higher share of immigrants produces a positive effect on attitudes only in wealthier areas (with approximately more than 25,000 euros per capita).

The results also reveal that the magnitude of both the main effects of share of immigrants and of the interaction effects are rather low. Referring to the coefficients in model 5 , an increase in share of immigrants by 10 per cent (the sample average) produces a direct increase of 0.03 in the attitudes score.

With regard to the effect of the other individual characteristics on attitudes, they are in line with previous literature (see Ceobanu and Escandell 2010, for an overview). Individuals with a higher educational attainment tend to have more positive attitudes towards immigrants. Occupational classification, which is strongly related to the educational level shows the same positive relationship with attitudes. According to the literature, better educated individuals are more tolerant and have higher personal security and autonomy (Dražanová 2017), have higher acceptance of diversity and higher exposure to foreign cultures (Hainmueller and Hiscox 2007). Our results also corroborate the evidence that individuals in more vulnerable situations (i.e. unemployed, low-skilled) may perceive immigrants as competitors in the labour market and 
therefore, have more negative attitudes towards immigrants. Individuals having a parent born abroad show more favourable attitudes towards immigrants; while those with more conservative ideologies have stronger antiimmigrant sentiment (Bohman 2011). Compared to those declaring to be placed in the left-side of the political spectrum, centrists and those having right-wing political orientation have lower attitudes towards immigrants. Results also show that demographic characteristics such as age, gender and place of residence are not relevant predictors of attitudes.

Finally, as complementary analysis, and to further explore the average results obtained before, we estimate the baseline models of Table 2 using the share of EU 27 immigrants and the share of non-EU 27 immigrants and their interactions with unemployment rate in model 1 and model 2, respectively (see Table 3). The conditioning effect of unemployment on attitudes is more relevant, both in magnitude and significance, for the EU 27 immigrants compared to the non-EU 27 immigrants. The same effect is found in model 3 and model 4, where the dependent variable is attitude towards immigrants on economic issues. Table $A 3$ in the supplemental online material shows that results are qualitatively similar for GDP per capita.

\section{Summary and conclusion}

Whether and how a higher presence of immigrants in the area of residence affects individuals' perceptions of immigrants has been a matter of great interest, both to researchers and to policy makers. Studies that have dealt with this

Table 3. Does the socioeconomic context condition the relationship between share of EU 27 and Non-EU 27 immigrants and attitudes (general and economic)?

\begin{tabular}{|c|c|c|c|c|}
\hline Variables & Model (1) & Model (2) & $\begin{array}{c}\text { Model (3) Economic } \\
\text { only }\end{array}$ & $\begin{array}{c}\text { Model (4) Economic } \\
\text { only }\end{array}$ \\
\hline Share Immigrants EU27 & $\begin{array}{l}0.00694^{* * *} \\
(0.00212)\end{array}$ & & $\begin{array}{l}0.00722^{* * *} \\
(0.00231)\end{array}$ & \\
\hline Unemployment & $\begin{array}{c}0.000508 \\
(0.000874)\end{array}$ & $\begin{array}{c}0.000159 \\
(0.000843)\end{array}$ & $\begin{array}{c}0.000162 \\
(0.000980)\end{array}$ & $\begin{array}{c}-0.000309 \\
(0.00097)\end{array}$ \\
\hline $\begin{array}{l}\text { Share Immigrants EU27 } \\
\text { *Unemployment }\end{array}$ & $\begin{array}{c}-0.00033^{* * *} \\
(0.000124)\end{array}$ & & $\begin{array}{c}-0.000330^{* *} \\
(0.000150)\end{array}$ & \\
\hline $\begin{array}{l}\text { Share Immigrants } \\
\text { nonEU27 }\end{array}$ & & $\begin{array}{l}0.00380^{* *} \\
(0.00147)\end{array}$ & & $\begin{array}{l}0.00335^{* *} \\
(0.00162)\end{array}$ \\
\hline $\begin{array}{l}\text { Share Immigrants } \\
\text { nonEU27 } \\
\text { * Unemployment }\end{array}$ & $-0.000196^{*}$ & $(0.000115)$ & -0.000168 & $(0.000130)$ \\
\hline Constant & $\begin{array}{l}0.369 * * * \\
(0.0176)\end{array}$ & $\begin{array}{l}0.378^{* * *} \\
(0.0172)\end{array}$ & $\begin{array}{l}0.320^{* * *} \\
(0.0197)\end{array}$ & $\begin{array}{l}0.334^{* * *} \\
(0.0192)\end{array}$ \\
\hline $\begin{array}{l}\text { Observations } \\
R \text {-squared }\end{array}$ & $\begin{array}{l}16,634 \\
0.212\end{array}$ & $\begin{array}{l}16,634 \\
0.211\end{array}$ & $\begin{array}{l}16,583 \\
0.197\end{array}$ & $\begin{array}{l}16,858 \\
0.196\end{array}$ \\
\hline
\end{tabular}

Dependent variable: Attitudes score. The estimation method used is OLS. All independent variables of Table 2 are included in the estimations. Country dummies included in the estimations. Error clustered at the NUTS3 level. Robust standard errors in parentheses. ${ }^{* * *} p<0.01,{ }^{* *} p<0.05,{ }^{*} p<0.1$. 
question have often based their explanations on contact and threat theories. They have asked: Does a higher presence of immigrants promote contact and, hence, mutual understanding and more positive attitudes? Or does it create feelings of threat associated with the development of different types of fears? However, and with some exceptions, these studies have often disregarded the complexities of the environment in which individuals live.

Using data from the European Social Survey (ESS7), in combination with aggregated data at the NUTS3 level, this study has set out to address this research gap. It explores whether the relationship between immigrant concentration and attitudes is conditioned by the socioeconomic characteristics of areas. To our knowledge, this is the first study that has addressed this research question from a cross-national perspective and with such low-level geographies. Our study finds evidence for this conditioning effect. Specifically, we find that the positive relationship between immigrant concentration and (positive) attitudes decreases as the socioeconomic condition of areas worsens. An important aspect of our findings is that such conditionality applies when comparing areas with medium socioeconomic conditions to those with good socioeconomic conditions. In areas with the poorest socioeconomic conditions, an increase in the concentration of immigrants does not seem to exert an influence on attitudes (at least not from a statistical point of view).

\section{Discussion}

From a theoretical perspective the results suggest, first of all, that contact theory is probably a suitable framework for explaining attitudes at the local level. In line with Weber (2015), we find a positive effect of immigrant concentration on attitudes. At the same time, the fact that attitudes become less positive as local socioeconomic conditions worsen might be an indication of threat explanations emerging - even if, contrary to expectations, they do not seem to play a role in areas with the poorest socioeconomic conditions.

Taken together, the results suggest that in wealthier NUTS3 areas, natives and immigrants might mix more, leading to increased social contact and, hence, to an alleviation of prejudice and stereotypes. This positive contact, would then diminish in areas with less (but not the poorest) socioeconomic resources. The fact that this effect is stronger when studying the spatial concentration of EU 27 migrants might in part explain this. On the one hand, these immigrants are less likely to be perceived as a threat overall, due to more cultural similarities. On the other, EU 27 immigrants have, in general, more similar educational levels to natives in destination countries, (compared to non-EU 27 immigrants) and their human capital is more easily transferable in the European labour market (Basilio, Bauer, and Kramer 2017). They might hence be perceived as competitors in the labour market (Mayda 2006; Hainmueller and Hiscox 2007), especially in areas with higher unemployment, 
where competition for jobs may exert further downward pressure on the wages of natives (Kunovich 2017). These suppositions should nevertheless be corroborated with more detailed data and can therefore be a matter of future investigation.

As to why we do not find an effect in poorer NUTS3 areas, we might hypothesize that it is associated with the sample size (for which we encourage researchers to study this phenomenon with different datasets). However, we might also think of an alternative explanation, associated to neighbourhood dynamics. In line with spatial assimilation theories, for which there is some evidence in Europe (Schaake, Burgers, and Mulder 2013; Zuccotti 2019), immigrants' neighbourhood segregation should diminish in areas with higher socioeconomic resources, since better-off immigrants often move to wealthier and whiter areas - while poorer immigrants remain constrained to ethnic enclaves. If this is the case, one explanation for the absence of an effect might be precisely the higher degree of residential and/or labour market segregation of immigrants in poorer NUTS3 areas, which would reduce both contact with natives and the threat of job competition (or competition for economic resources). In other words, if in poorer NUTS3 areas, immigrants and natives have fewer opportunities to actually confront in the streets, at work, etc., it is therefore plausible that an increase in the share of immigrants at the NUTS3 level has little impact on attitudes: most of the increase might remain unknown to natives residing there. In line with this argument, preliminary evidence in the US shows that minority group segregation diminishes the impact of material threat on attitudes towards black people (Oliver and Mendelberg 2000) and preferences towards Latino immigrants (Rocha and Espino 2009). This is something that would deserve future exploration too.

From a policy perspective, our work contributes to the vivid debate on the optimal settlement of incoming immigrants and asylum seekers. Policy research has often focused on the spatial distribution of immigrants and the impact this may have on a series of objective and subjective outcomes, both for the immigrants themselves and the wider society. Our work emphasizes that a policy promoting the spatial distribution of immigrants should consider the socioeconomic characteristics of the areas in which they will reside. Essentially, this study suggests that directing or allocating immigrants to areas that have higher socioeconomic resources might foster immigrants' acceptance by the native population, and hence be a good strategy for improving a society's social cohesion.

\section{Notes}

1. Nomenclature of territorial units for statistics (NUTS), is a geographical nomenclature subdividing the European Union into regions at three different levels (1, 2 and 3 moving from larger to smaller). The definition of NUTS3 includes areas with a size between 150,000 and 800,000 inhabitants. 
2. Note that a value is obtained even with missing responses in some of the questions.

3. Although perhaps less so to proxy competition for social services, like schools and housing, which might occur at a lower level (municipality, neighbourhood).

4. Census data for year 2011 is the closest to 2014-15 (years of the survey) we could obtain for all countries. https://ec.europa.eu/eurostat/web/populationand-housing-census/census-data/2011-census. There is a mismatch between the year of ESS (2014) and the year of contextual variables and census (2011). We think that this short time lag does not distort our baseline results as we do not expect relevant distributional changes in the shares of immigrants and socioeconomic variables across NUTS3 areas between 2011 and 2014. Moreover, for most of the countries, ESS (2014) collects information on attitudes just before the start of the massive inflow of immigrants in 2015. One exception is Poland where the interviews where collected from April to September 2015. Excluding Poland from the estimates does not change significantly the results. Results are available upon request.

5. Note that this method does not take into account the spatial dependence of anti-immigration attitudes across NUTS3 geographies.

6. We categorize education following the original classification used by ESS. Differently from the ISCED 1997 classification, the ESS divides the upper secondary education (ISCED 3) class in 2 sub-classes. See Table A4 in the Supplemental material for more details.

7. The coefficient of an interaction is statistically significant across the values of the conditioning variable when the upper and lower bound of the 95 per cent confidence interval (dashed lines in the graph) are both above or below the flat 0 line.

\section{Acknowledgements}

A special thank you to the ESS board and country team members, for facilitating the data. We also thank the comments of our MEDAM and MPC colleagues, and those of external reviewers.

\section{Disclosure statement}

No potential conflict of interest was reported by the author(s).

\section{Funding}

This research was supported by the Stiftung Mercator [grant number PN 14-297] and is part of project MEDAM - Mercator Dialogue on Migration and Asylum.

\section{ORCID}

Carolina V. Zuccotti (D) http://orcid.org/0000-0001-8374-2963

\section{References}

Allport, Gordon W. 1954. The Nature of Prejudice. Reading, MA: Addison Wesley. 
Basilio, Leilanie, Thomas K. Bauer, and Anica Kramer. 2017. "Transferability of Human Capital and Immigrant Assimilation: An Analysis for Germany." Labour (Committee on Canadian Labour History) 31 (3): 245-264. doi:10.1111/labr.12096.

Billiet, Jaak, Bart Meuleman, and Hans De Witte. 2014. "The Relationship Between Ethnic Threat and Economic Insecurity in Times of Economic Crisis: Analysis of European Social Survey Data." Migration Studies 2 (2): 135-161. doi:10.1093/migration/mnu023. Blalock, H. M. 1967. Toward a Theory of Minority-Group Relations. New York: Wiley.

Blumer, Herbert. 1958. "Race Prejudice as a Sense of Group Position." Pacific Sociological Review 1 (1): 3-7. doi:10.2307/1388607.

Bohman, Andrea. 2011. "Articulated Antipathies: Political Influence on Anti-Immigrant Attitudes." International Journal of Comparative Sociology 52 (6): 457-477. doi:10. $1177 / 0020715211428182$.

Boyle, Paul, Paul Norman, and Philip Rees. 2004. “Changing Places. Do Changes in the Relative Deprivation of Areas Influence Limiting Long-Term Illness and Mortality among non-Migrant People Living in non-Deprived Households?" Social Science \& Medicine 58 (12): 2459-2471. doi:10.1016/j.socscimed.2003.09.011.

Brambor, Thomas, William Roberts Clark, and Matt Golder. 2006. "Understanding Interaction Models: Improving Empirical Analyses." Political Analysis 14 (1): 63-82.

Branton, Regina P., and Bradford S. Jones. 2005. "Reexamining Racial Attitudes: the Conditional Relationship Between Diversity and Socioeconomic Environment." American Journal of Political Science 49 (2): 359-372. doi:10.1111/j.0092-5853.2005. 00128.x.

Callens, Marie-Sophie, and Bart Meuleman. 2017. "Do Integration Policies Relate to Economic and Cultural Threat Perceptions? A Comparative Study in Europe." International Journal of Comparative Sociology 58 (5): 367-391. doi:10.1177/ 0020715216665437.

Ceobanu, Alin M., and Xavier Escandell. 2010. "Comparative Analyses of Public Attitudes Toward Immigrants and Immigration Using Multinational Survey Data: A Review of Theories and Research." Annual Review of Sociology 36 (1): 309-328. doi:10.1146/annurev.soc.012809.102651.

Citrin, Jack, Donald P. Green, Christopher Muste, and Cara Wong. 1997. "Public Opinion Toward Immigration Reform: the Role of Economic Motivations." The Journal of Politics 59 (3): 858-881. doi:10.2307/2998640.

Coenders, Marcel, and Peer Scheepers. 2008. "Changes in Resistance to the Social Integration of Foreigners in Germany 1980-2000: Individual and Contextual Determinants." Journal of Ethnic and Migration Studies 34 (1): 1-26. doi:10.1080/ 13691830701708809.

Collins, Patricia Hill. 2015. "Intersectionality's Definitional Dilemmas." Annual Review of Sociology 41 (1): 1-20. doi:doi:10.1146/annurev-soc-073014-112142.

Davidov, Eldad, Jan Cieciuch, and Peter Schmidt. 2018. "The Cross-Country Measurement Comparability in the Immigration Module of the European Social Survey 2014-15." Survey Research Methods 12 (1): 13. doi:10.18148/srm/2018.v12i1.7212.

Dražanová, Lenka. 2017. Education and Tolerance. A Comparative Quantitative Analysis of the Educational Effect on Tolerance. Bern: Peter Lang D.

Dustmann, Christian, and lan Preston. 2001. "Attitudes to Ethnic Minorities, Ethnic Context and Location Decisions." The Economic Journal 111 (470): 353-373. doi:10. 1111/1468-0297.00611.

European Social Survey Round 7 Data. 2014. "Data File Edition 2.2." NSD - Norwegian Centre for Research Data, Norway - Data Archive and Distributor of ESS Data for ESS ERIC. doi:10.21338/NSD-ESS7-2014. 
Feng, Xiaoqi, Robin Flowerdew, and Zhiqiang Feng. 2015. “Does Neighbourhood Influence Ethnic Inequalities in Economic Activity? Findings from the ONS Longitudinal Study." Journal of Economic Geography 15 (1): 169-194. doi:10.1093/ jeg/lbt036.

Eurostat. 2014. The 2011 Census Hub. https://ec.europa.eu/eurostat/web/populationand-housing-census/census-data/2011-census.

Fleischmann, Fenella, Karen Phalet, Patrick Deboosere, and Karel Neels. 2012. "Comparing Concepts of Ethnicity in Ethnic Composition Measures: Local Community Contexts and the Educational Attainment of the Second Generation in Belgium." Journal of Ethnic and Migration Studies 38 (10): 1513-1531. doi:10. 1080/1369183x.2012.711033.

Ganzeboom, Harry, and Donald Treiman. 1996. "Internationally Comparable Measures of Occupational Status for the 1988 International Standard Classification of Occupations." Social Science Research 25: 201-239. doi:10.1006/ssre.1996.0010.

Hainmueller, Jens, and Michael J. Hiscox. 2007. "Educated Preferences: Explaining Attitudes Toward Immigration in Europe." International Organization 61 (2): 399442. doi:10.1017/S0020818307070142.

Hainmueller, Jens, Jonathan Mummolo, and Yiqing Xu. 2018. "How Much Should We Trust Estimates from Multiplicative Interaction Models? Simple Tools to Improve Empirical Practice." Political Analysis 27 (2): 163-192. doi:10.1017/pan.2018.46.

Hjerm, Mikael. 2007. "Do Numbers Really Count? Group Threat Theory Revisited." Journal of Ethnic and Migration Studies 33 (8): 1253-1275. doi:10.1080/ 13691830701614056.

Hjerm, Mikael. 2009. "Anti-immigrant Attitudes and Cross-Municipal Variation in the Proportion of Immigrants." Acta Sociologica 52 (1): 47-62. doi:10.1177/ 0001699308100633.

Hooghe, Marc, and Thomas de Vroome. 2015. "The Perception of Ethnic Diversity and Anti-Immigrant Sentiments: a Multilevel Analysis of Local Communities in Belgium." Ethnic and Racial Studies 38 (1): 38-56. doi:10.1080/01419870.2013.800572.

Kaufmann, Eric, and Gareth Harris. 2015. "'White Flight" or Positive Contact? Local Diversity and Attitudes to Immigration in Britain." Comparative Political Studies 48 (12): 1563-1590. doi:10.1177/0010414015581684.

Kunovich, Robert M. 2017. "Labour Market Competition and Immigration Attitudes in an Established Gateway." Ethnic and Racial Studies 40 (11): 1961-1980. doi:10. 1080/01419870.2016.1237670.

Markaki, Yvonni, and Simonetta Longhi. 2013. "What Determines Attitudes to Immigration in European Countries? An Analysis at the Regional Level." Migration Studies 1 (3): 311-337. doi:10.1093/migration/mnt015.

Mayda, Anna Maria. 2006. "Who is Against Immigration? A Cross-Country Investigation of Individual Attitudes Toward Immigrants." The Review of Economics and Statistics 88 (3): 510-530. doi:10.1162/rest.88.3.510.

O'Rourke, Kevin H., and Richard Sinnott. 2006. "The Determinants of Individual Attitudes Towards Immigration." European Journal of Political Economy 22 (4): 838-861. doi:10.1016/j.ejpoleco.2005.10.005.

Oliver, J. Eric, and Tali Mendelberg. 2000. "Reconsidering the Environmental Determinants of White Racial Attitudes." American Journal of Political Science 44 (3): 574-589. doi:10.2307/2669265.

Pettigrew, Thomas F. 1998. "Intergroup Contact Theory." Annual Review of Psychology 49 (1): 65-85. doi:10.1146/annurev.psych.49.1.65. 
Pettigrew, Thomas F., and Linda R. Tropp. 2006. "A Meta-Analytic Test of Intergroup Contact Theory." Journal of Personality and Social Psychology 90 (5): 751-783.

Quillian, Lincoln. 1995. "Prejudice as a Response to Perceived Group Threat: Population Composition and Anti-Immigrant and Racial Prejudice in Europe." American Sociological Review 60 (4): 586-611.

Rocha, Rene R., and Rodolfo Espino. 2009. "Racial Threat, Residential Segregation, and the Policy Attitudes of Anglos." Political Research Quarterly 62 (2): 415-426. doi:10. 1177/1065912908320931.

Ruist, Joakim. 2016. "How the Macroeconomic Context Impacts on Attitudes to Immigration: Evidence From Within-Country Variation." Social Science Research 60: 125-134. doi:10.1016/j.ssresearch.2016.04.018.

Schaake, Karina, Jack Burgers, and Clara H. Mulder. 2013. "Ethnicity, Education and Income, and Residential Mobility Between Neighbourhoods." Journal of Ethnic and Migration Studies 40 (4): 512-527. doi:10.1080/1369183x.2013.830500.

Semyonov, Moshe, and Anya Glikman. 2009. "Ethnic Residential Segregation, Social Contacts, and Anti-Minority Attitudes in European Societies." European Sociological Review 25 (6): 693-708. doi:10.1093/esr/jcn075.

Stafford, Mai, Mel Bartley, Amanda Sacker, Michael Marmot, Richard Wilkinson, Richard Boreham, and Roger Thomas. 2003. "Measuring the Social Environment: Social Cohesion and Material Deprivation in English and Scottish Neighbourhoods." Environment and Planning A: Economy and Space 35 (8): 1459-1475. doi:10.1068/ a35257.

Tam Cho, Wendy K., and Neil Baer. 2011. "Environmental Determinants of Racial Attitudes Redux: the Critical Decisions Related to Operationalizing Context." American Politics Research 39 (2): 414-436. doi:10.1177/1532673×10377167.

Verardi, Vincenzo, and Christophe Croux. 2009. "Robust Regression in Stata." The Stata Journal 9 (3): 439-453. doi:10.1177/1536867x0900900306.

Wang, Xia, and Natalie Todak. 2016. "Racial Threat Hypothesis." OBO in Criminology. doi:10.1093/obo/9780195396607-0204.

Weber, Hannes. 2015. "National and Regional Proportion of Immigrants and Perceived Threat of Immigration: A Three-Level Analysis in Western Europe." International Journal of Comparative Sociology 56 (2): 116-140. doi:10.1177/0020715215571950.

Zuccotti, Carolina V. 2019. "Ethnicity and Neighbourhood Attainment in England and Wales: A Study of Second Generations' Spatial Integration." Population, Space and Place, e2252. doi:10.1002/psp.2252. 